\title{
A Randomized, Crossover, Pharmacokinetic and Adhesion Performance Study of a Lidocaine Topical System 1.8\% During Physical Activity and Heat Treatment in Healthy Subjects
}

This article was published in the following Dove Press journal:

Journal of Pain Research

\author{
Jeffrey Fudin (iD) ${ }^{1-4}$ \\ Erica L Wegrzyn ${ }^{1-3}$ \\ Emileigh Greuber $\mathbb{D D}^{5}$ \\ Kip Vought ${ }^{5}$ \\ Kalpana Patel ${ }^{5}$ \\ Sri Nalamachu ${ }^{6}$ \\ 'Samuel Stratton Department of \\ Veterans Affairs Medical Center, Albany, \\ NY, USA; ${ }^{2}$ Albany College of Pharmacy \& \\ Health Sciences, Albany, NY, USA; \\ ${ }^{3}$ Western New England University \\ College of Pharmacy, Springfield, MA \\ USA; ${ }^{4}$ Remitigate, LLC, Delmar, NY, \\ USA; ${ }^{5}$ Scilex Pharmaceuticals Inc., \\ Mountain View, CA, USA; ${ }^{6}$ Mid America \\ PolyClinic, Overland Park, KS, USA
}

Correspondence: Jeffrey Fudin Remitigate, LLC, Delmar, NY 12054, USA $\mathrm{Tel}+1$ 5I8-772-4100

$\mathrm{Fax}+\mid$ 518-734-0288

Email jeff@paindr.com
Purpose: This study compares the pharmacokinetic (PK) profile, adhesion, and safety of lidocaine topical system $1.8 \%$, a novel lidocaine topical system approved to treat postherpetic neuralgia, under conditions of heat and exercise vs normal conditions.

Materials and Methods: This open-label, 3-period, 3-treatment crossover study randomized 12 healthy adults to receive three lidocaine topical systems $1.8 \%$ during each of three treatment periods, with 7-day washouts between treatments. The product was applied to the mid-lower back and was removed after 12 hours. During Treatment A, subjects exercised on a bicycle for 30 minutes at $0,2.5,5.5$, and 8.5 hours. During Treatment B, heat (temperature set at $36.7-40.3^{\circ} \mathrm{C}$ ) was applied at 0 and 8.5 hours. Treatment $\mathrm{C}$ was normal conditions. The PK profile of each subject under exercise and heat conditions was compared to normal conditions. Skin irritation, adhesion, and adverse events were assessed.

Results: Twelve subjects completed the study. Exposure to external heat resulted in increased peak plasma concentration of lidocaine with a mean $C_{\max }$ of $160.3 \pm 100.1 \mathrm{ng} / \mathrm{mL}$ vs $97.6 \pm 36.9 \mathrm{ng} / \mathrm{mL}$ under normal conditions, with no effect on the extent of exposure (AUC). Concentrations returned to normal within 4 hours after the heat was removed. No clinically relevant differences in absorption were observed under exercise conditions with a mean $\mathrm{C}_{\max }$ of $90.5 \pm 25.4 \mathrm{ng} / \mathrm{mL}$ and no effect on the extent (AUC) of lidocaine exposure was observed relative to normal conditions. No systems detached during the study. Adverse events were mild, with none leading to discontinuation.

Conclusion: Transient heat exposure resulted in increased lidocaine plasma concentrations compared to normal conditions, whereas exercise had no effect. The effects of heat appear to be immediate, reversible, and below systemic therapeutic threshold in antiarrhythmic treatment $(1000-1500 \mathrm{ng} / \mathrm{mL})$, and well below the safe systemic threshold of $5000 \mathrm{ng} / \mathrm{mL}$. Lidocaine topical system $1.8 \%$ remained adhered to the skin and was well tolerated under all conditions. ClinicalTrials.gov: NCT04150536.

Keywords: herpes zoster, shingles, neuropathic pain, dermal

\section{Introduction}

Postherpetic neuralgia (PHN) is a chronic neuropathic pain condition that is a common complication of herpes zoster virus infections (shingles), particularly in older patients. The pain may persist for several $(>3)$ months after the rash has resolved and is described as burning, sharp, jabbing, deep, and aching; it may be associated with allodynia. Itching and numbness have also been reported. PHN 
presents a significant individual and societal healthcare burden, but is often undiagnosed and poorly managed, with a $30 \%$ pain reduction considered clinically significant but a goal that is only met about $50 \%$ of the time. ${ }^{1}$

Before prescribing treatment for PHN, providers must consider several patient-specific factors, such as age, comorbidities, and any medications used for treating comorbidities, to avoid potentially additive side effects. As the incidence of PHN increases with age, ${ }^{2}$ it is also important to consider age-related physiologic changes and pharmacokinetic (PK) implications, including impaired hepatic and renal function, that can increase the risk of adverse events (AEs). ${ }^{3}$ This is important given the potential AE profiles of oral medications for PHN that may include serotonin-norepinephrine reuptake inhibitors, tricyclic antidepressants, gabapentinoids, anticonvulsants, and opioids. $^{4-6}$

Lidocaine is an amide local anesthetic agent that stabilizes neuronal membranes by inhibiting the ionic fluxes required for initiation and conduction of impulses. Application of topical lidocaine has been shown to be efficacious for the treatment of neuropathic pain, with a low risk of systemic effects. ${ }^{1,2}$ ZTlido $^{\circledR}$ is a novel lidocaine topical system (Scilex Pharmaceuticals Inc., Mountain View, CA, USA) that was approved by the US FDA in 2018 for the relief of pain associated with PHN. Each topical system contains $36 \mathrm{mg}$ of lidocaine in a thin, nonaqueous adhesive matrix (18 $\mathrm{mg}$ per gram adhesive: $1.8 \%){ }^{7}$ Lidocaine topical system $1.8 \%$ was developed to deliver a bioequivalent level of the drug as Lidoderm ${ }^{\circledR}$ (lidocaine patch 5\%; Endo Pharmaceuticals, Malvern, PA, USA), a hydrogel patch containing $700 \mathrm{mg}$ of lidocaine. ${ }^{8}$ Like Lidoderm, ZTlido was designed to deliver sufficient lidocaine to produce an analgesic effect, but less than that needed to produce a complete sensory block. ${ }^{7}$

Systemic lidocaine exposure from topically applied patches (now referred to as "topical systems" by FDA) is limited under normal wear conditions. For many drugs, however, delivery through the skin, and thus serum drug concentrations, can be affected by heat and exercise, which may alter circulation and blood flow, resulting in increased drug delivery and higher drug exposure. ${ }^{9,10}$ It is known that the absorption of local anesthetic agents, including lidocaine, from topical creams, can be increased if skin temperature is elevated by exercising, covering the skin, or using an external heat source. ${ }^{11}$ There have been reports of serious adverse events, including irregular heartbeat, seizures, difficulty breathing, and death after the improper use of local anesthetic numbing creams. ${ }^{11}$ The concentration of lidocaine required for systemic toxicity is $\geq 5000 \mathrm{ng} / \mathrm{mL}^{12}$ which is several-fold higher than the systemic exposure from prescription lidocaine patches and systems $(\sim 100$ $\mathrm{ng} / \mathrm{mL}$ ) under normal use conditions. ${ }^{7,8}$ The effects of heat and exercise on drug delivery are dependent on many factors, including drug load, concentration, and the inactive ingredient composition, and should, therefore, be determined on a product-specific basis.

Adhesion under conditions of heat and exercise is also a potential concern, as drug delivery depends on product adherence to the skin throughout the administration period. Activities of daily living can impact the application of topical systems and ultimately decrease efficacy if dermal adhesion is poor.

Consistent with regulatory expectations and to appropriately characterize and label the product, this study was conducted to characterize the PK and adhesion of lidocaine topical system $1.8 \%$ under conditions of heat and exercise.

\section{Materials and Methods Measures and Outcomes}

This open-label, randomized, 3-treatment, 3-sequence, 3-period crossover study was conducted at one clinical site (AXIS Clinicals, Dilworth, MN, USA) in accordance with ICH Guideline for Good Clinical Practice (GCP), approved by Salus Institutional Review Board (IRB), and conducted in accordance with the Declaration of Helsinki. The bioanalytical facility was blinded to the randomization code. This study was registered with ClinicalTrials.gov, NCT04150536.

\section{Study Objectives}

The primary objective of this study was to evaluate the PK characteristics and adhesion performance of lidocaine topical system $1.8 \%$ (administered as 3 topical systems) in fasting healthy human subjects during physical exercise, heat exposure, and normal conditions. The secondary objective was to conduct a formal irritation assessment at the end of each treatment period and to monitor AEs and safety concerns in healthy subjects with the use of the product.

\section{Subjects}

Eligible men and women were 18 years of age and older, with a body mass index (BMI) between 18.00 and $32.49 \mathrm{~kg} / \mathrm{m}^{2}$. Subjects were generally healthy, as documented by medical history, physical examination, and 
vital signs assessments, with no evidence of underlying disease during check-in and screening performed within 28 days of check-in. Female subjects were not pregnant and used contraception during the study if they were of child-bearing potential. All subjects provided written informed consent and were able to comply with study procedures.

\section{Exclusion Criteria}

Subjects were excluded if they had any major medical illness 3 months prior or any significant history or ongoing chronic medical illness affecting the major body systems, including the skin; allergy or known hypersensitivity to lidocaine, amide-type local anesthetics, or any component of the product formulation. Subjects with conditions that might affect the application of the product or its adhesive properties (including psoriasis, eczema, atopic dermatitis, damaged or irritated epidermal layer, and excessive hair or oil on the skin) were excluded. History of addiction, abuse, and misuse of any drug; use of any nicotine-containing products within 30 days; or alcohol abuse within 12 months prior to product application were also reasons for study exclusion.

\section{Treatments}

Per randomization schedule, all subjects received three lidocaine topical systems $1.8 \%$, each containing $36 \mathrm{mg}$ of lidocaine, during three separate treatment periods (Period-I, Period-II, Period-III). Each period included four subjects per treatment (Treatments A, B, C). Subjects were randomized to three different treatment sequences $(\mathrm{ABC}, \mathrm{BCA}$, and $\mathrm{CAB})$. In each period, the product was applied to clean, dry skin that was free of lotion, soap, or oil in the mid-lower back after an overnight fast ( $\geq 10$ hours) in each of three randomly allocated treatment plans, with a 7-day washout between treatments. The three topical systems (total lidocaine dose of $108 \mathrm{mg}$ ) were each worn for 12 hours. No overlays, adhesive tape, or similar products were applied.

- Treatment A: 3 lidocaine topical systems $1.8 \%$ with physical exercise

- Treatment B: 3 lidocaine topical systems 1.8\% with application of heat

- Treatment C: 3 lidocaine topical systems 1.8\% under normal conditions

\section{Physical Exercise}

Subjects were instructed to perform an exercise regimen for 30 minutes on an exercise bicycle (Exerpeutic 1000-High Capacity Magnetic Recumbent Exercise Bike, Exerpeutic, China), achieving a heart rate of approximately 108 beats per minute. Exercise was performed immediately after product application and at 2.5, 5.5, and 8.5 hours after product application, with a window of \pm 10 minutes. Heart rate was continuously monitored during exercise.

\section{Heat Application}

Heat was applied using a standard 3-setting heating pad (CVS XL 3 Setting Moist Dry Heating Pad and Controller), with precautions followed for heat application per manufacturer guidelines (ie, a blanket or towel placed between the pad and the product to reduce risk of skin burning). The temperature was set on "medium" $\left(36.7-40.3^{\circ} \mathrm{C}\right.$ tested over 1 hour with Etekcity Lasergrip 774 Infrared Thermometer, Etekcity Corporation, Anaheim, CA, USA), and the heating pad was applied for 20 minutes immediately and at 8.5 hours after product application.

\section{Study Assessments}

The PK of each treatment condition was evaluated by the estimation of lidocaine concentrations in plasma, using a validated liquid chromatography-tandem mass spectrometry (LC-MS/MS) method. The calibration range of the procedure was $0.2000 \mathrm{ng} / \mathrm{mL}$ to $200.0 \mathrm{ng} / \mathrm{mL}$, with a lower limit of quantification of $0.2000 \mathrm{ng} / \mathrm{mL}$. PK parameters such as maximum plasma concentration $\left(\mathrm{C}_{\max }\right)$, area under the plasma concentration-time curve between times zero and $\mathrm{t}\left(\mathrm{AUC}_{0-\mathrm{t}}\right)$, AUC between time zero and infinity $\left(\mathrm{AUC}_{0-\infty}\right)$, time to $\mathrm{C}_{\max }\left(\mathrm{t}_{\max }\right)$, percentage extrapolation (calculated as $\mathrm{AUC}_{\% \text { extrapolation }}=\left[\mathrm{AUC}_{0-\infty}-\mathrm{AUC}_{0-\mathrm{t}}\right]$ $\left.\times 100 / \mathrm{AUC}_{0-\infty}\right)$, elimination rate constant $\left(\mathrm{K}_{\mathrm{el}}\right)$, and elimination half-life $\left(t_{1 / 2}\right)$ were calculated following blood collection by venipuncture pre-dose and at $2,4,6,9,10$, $11,12,13,14,16,18,20,22,24$, and 48 hours post-dose.

Skin irritation at the lidocaine topical system application site was evaluated pre-application ( 0 hours), 30 minutes (with a window period of \pm 10 minutes) after product removal and 2 hours after product removal using the FDA-recommended 8-point scale of dermal response $(0=$ no evidence of irritation; $1=$ =minimal erythema, barely perceptible; $2=$ definite erythema; $3=$ erythema and papules/pustules; $4=$ definite edema; $5=$ erythema, edema, and papules; $6=$ vesicular eruption; 
$7=$ strong reaction spreading beyond the test site) and a scale of other effects (including glazed appearance, peeling and cracking, dried serous exudates covering at least part of the application site, and small petechial erosions and/or scabs). ${ }^{13}$ Product adhesion was assessed immediately after (0 hours) and at 0.5, 3, 6, 9, and 12 hours (before system removal) after application, with a degree of adhesion recorded using the FDArecommended rating scale, where $0: \geq 90 \%$ adhered (essentially no lift off the skin); $1: \geq 75 \%$ to $<90 \%$ adhered (some edges only lifting off the skin); $2: \geq 50 \%$ to $<75 \%$ adhered (less than half the system lifting off the skin); $3:<50 \%$ adhered but not detached (more than half the system lifting off the skin without falling off); and 4 : $0 \%$ (complete detachment). ${ }^{14}$

\section{Statistical Analysis}

The randomization schedule was prepared using $\mathrm{SAS}^{\circledR}$ Release 9.4 (SAS Institute Inc., Cary, NC, USA). Data set preparation and analysis of the $\mathrm{PK}$ parameters were performed using a non-compartmental model with WinNonlin Professional Software version 5.01 (Pharsight Corporation, Sunnyvale, CA, USA).

Descriptive statistics were computed for all PK parameters for lidocaine topical system $1.8 \%$ (total lidocaine dose $=108 \mathrm{mg}$ ) under each treatment condition (exercise, heat, and normal). Bioequivalence comparisons of PK parameters for the exercise and heat treatments vs normal conditions were performed using PROC GLM of SAS ${ }^{\circledR}$ Release 9.4. Analysis of variance (ANOVA) was calculated for untransformed and natural log-transformed $\mathrm{C}_{\max }, \mathrm{AUC}_{0-\mathrm{t}}$, and $\mathrm{AUC}_{0-\infty}$ using the treatment received, the period at which it was given, the sequence of treatment, and the subject effect (nested within the sequence). Sequence effect was tested using the subject nested within sequence mean square from the ANOVA as the error term. ANOVA calculations included least square mean. The level of significance was set at $\alpha=0.05$, except for the significance of the sequence effect involved in the model (set at $\alpha=0.1$ ). $90 \%$ confidence intervals (CIs) for the ratio of the Treatments (A, B and C) products averages (geometric least-square means) were calculated by first calculating the $90 \%$ CI for the differences in the averages (least-square means) of the log-transformed data and then taking the antilogs of the obtained confidence limits. By convention, if the $90 \% \mathrm{CI}$ of the ratio of geometric means was within $80 \%$ to $125 \%$, then the treatments were considered bioequivalent.

\section{Adverse Events and Safety}

AEs were recorded after spontaneous reporting by subject or physician observation within \pm 30 minutes of the scheduled time. Vital sign assessments (blood pressure, heart rate, respiratory rate and temperatures) were taken at pre-dose, 4, 10, and 24 hours post-dose. A 12-lead electrocardiogram was recorded at screening (all within normal limits).

\section{Results}

\section{Subject Disposition and Baseline Characteristics}

A total of 12 subjects, aged between 19 and 62 years with BMI values between 21.95 and $30.91 \mathrm{~kg} / \mathrm{m}^{2}$ (Table 1), completed the study. Subjects were randomized to each of the three treatments according to the predetermined schedule; all subjects completed their assigned schedule without any discontinuations or withdrawals. Plasma concentrations of 12 subjects were included in PK and statistical analyses; all subjects were included in the adhesion analysis.

\section{PK Assessments}

\section{Comparison of Physical Exercise and Normal Conditions}

Mean values of the primary $\mathrm{PK}$ parameters $\mathrm{C}_{\max }, \mathrm{AUC}_{0-\mathrm{t}}$, and $\mathrm{AUC}_{0-\infty}$ were lower during physical exercise (Treatment $\mathrm{A}$ ) than during normal conditions (Treatment $\mathrm{C}$ ) by $7 \%, 11 \%$, and $10 \%$, respectively.

The $90 \%$ confidence interval for physical exercise (Treatment A) vs normal conditions (Treatment C) ratios of Ln-transformed PK parameters fell within the range of 79.65 to 112.73, suggesting that the effects of physical exercise on the rate and extent of lidocaine absorption from the topical system were not significant (Figure 1, Tables 2 and 3).

The median plasma lidocaine $\mathrm{t}_{\max }$ was 9 hours for physical exercise (Treatment A) and 11.5 hours for normal conditions (Treatment $C$ ). The observed half-life was similar for Treatment A (5.602 hours) and Treatment C (5.230 hours) (Figure 1, Tables 2 and 3).

Table I Demographics and Baseline Characteristics

\begin{tabular}{|l|l|}
\hline & $\mathbf{N}=12$ \\
\hline Age, years, mean \pm SD (range) & $46.17 \pm 15.94$ (19-62) \\
Sex, $\mathrm{n}, \mathrm{M} / \mathrm{F}$ & $3 / 9$ \\
Race, $\mathrm{n}, \mathrm{Black} /$ White & $\mathrm{I} / \mathrm{II}$ \\
BMl, $\mathrm{kg} / \mathrm{m}^{2}$ (mean $\left.\pm S D\right)$ & $27.81 \pm 2.91$ \\
\hline
\end{tabular}

Abbreviations: SD, standard deviation; BMI, body mass index. 


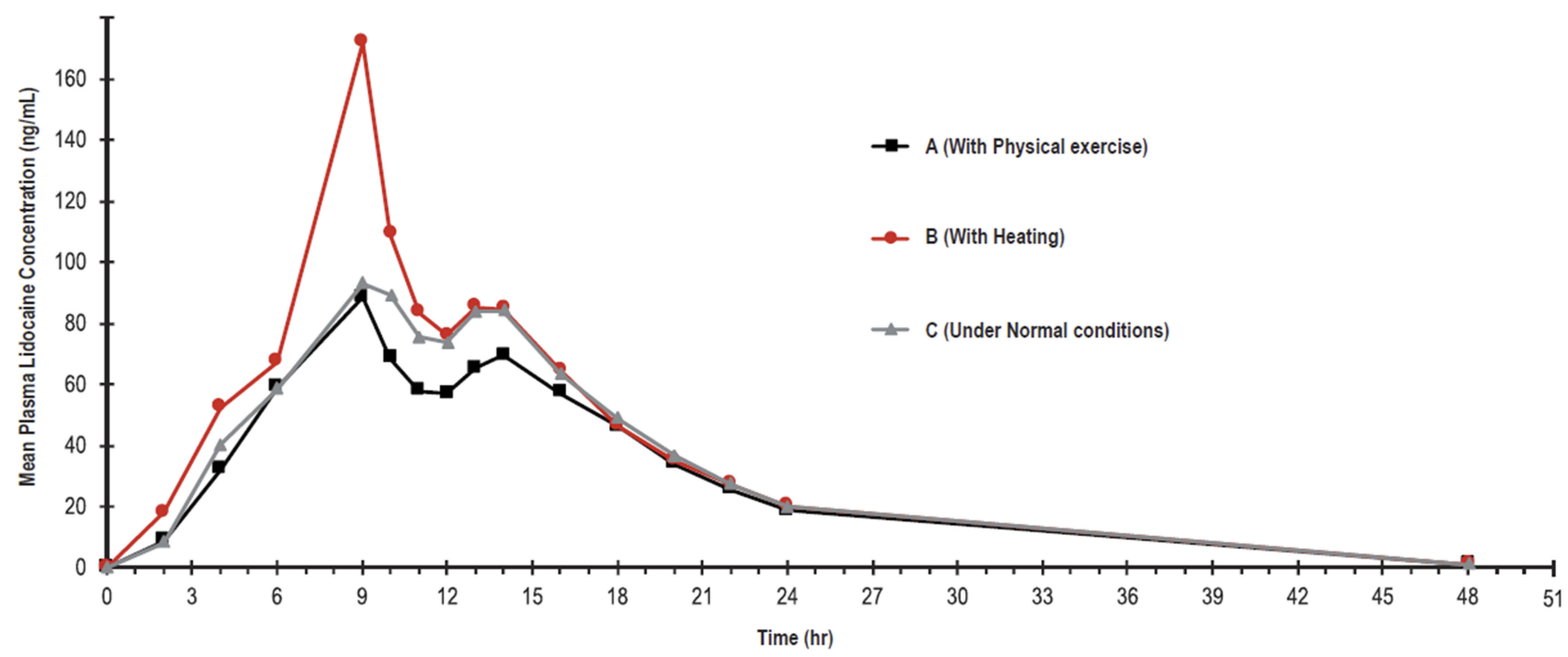

Figure I Mean plasma lidocaine concentration after application of three lidocaine topical systems ( $1.8 \%$; $108 \mathrm{mg})$ vs time with physical exercise, heat exposure, and under normal conditions. Treatment A: with physical exercise; Treatment B: with heating; Treatment C: under normal conditions.

\section{Comparison of Heating and Normal Conditions}

The mean values of $\mathrm{C}_{\max }, \mathrm{AUC}_{0-\mathrm{t}}$, and $\mathrm{AUC}_{0-\infty}$ were higher during heat application (Treatment $\mathrm{B}$ ) than during normal conditions (Treatment C) by $64 \%, 16 \%$, and $15 \%$, respectively (Figure 1, Tables 2 and 3).

The $90 \%$ confidence interval for heat application (Treatment B) vs normal conditions (Treatment $\mathrm{C}$ ) ratios of Ln-transformed $\mathrm{C}_{\max }(123.71-173.66 \mathrm{ng} / \mathrm{mL})$ fell outside the $80 \%$ to $125 \%$ limits that are standard for bioequivalence determination, suggesting that heat exposure caused a significant increase in lidocaine absorption, resulting in a higher $\mathrm{C}_{\max }$ than under normal conditions (Figure 1, Tables 2 and 3).

The corresponding ranges for $\mathrm{AUC}_{0-\mathrm{t}}(95.34-122.40$ $\mathrm{h} \cdot \mathrm{ng} / \mathrm{mL})$ and $\mathrm{AUC}_{0-\infty}(95.46-121.79 \mathrm{~h} \cdot \mathrm{ng} / \mathrm{mL})$ were within the $80 \%$ to $125 \%$ range, suggesting that the effects of heating on these parameters were not significant (Figure 1, Tables 2 and 3).

Table 2 Summary Statistics of Pharmacokinetic Parameters of Lidocaine Topical System I.8\% with Physical Exercise, Heating, and Normal Conditions

\begin{tabular}{|c|c|c|c|c|c|c|c|c|}
\hline \multicolumn{2}{|l|}{ Statistics } & \multirow{2}{*}{$\begin{array}{l}\mathrm{C}_{\max } \\
(\mathrm{ng} / \mathrm{mL})\end{array}$} & \multirow{2}{*}{ 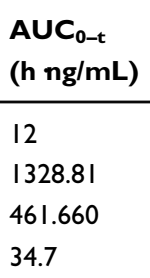 } & \multirow{2}{*}{$\begin{array}{l}\text { AUC }_{\mathbf{0}_{-\infty}} \\
\text { (h ng/mL) }\end{array}$} & \multirow{2}{*}{$\begin{array}{l}\text { AUC\% } \\
\text { Extrapolation } \\
12 \\
1.36 \\
2.211 \\
162.3\end{array}$} & \multirow{2}{*}{$\begin{array}{l}\mathbf{t}_{\max } *(\mathbf{h}) \\
12 \\
9.00 \\
9.00-18.00 \\
30.0\end{array}$} & \multirow{2}{*}{$\begin{array}{l}\mathbf{K}_{\mathrm{el}}\left(\mathbf{h}^{-1}\right) \\
12 \\
0.13 \\
0.024 \\
18.9\end{array}$} & \multirow{2}{*}{$\begin{array}{l}\mathbf{t}_{1 / 2} \\
\text { (h) }\end{array}$} \\
\hline Treatment A & $\begin{array}{l}\mathrm{N} \\
\text { Mean } \\
\mathrm{SD} \\
\mathrm{CV}(\%)\end{array}$ & & & & & & & \\
\hline Treatment B & $\begin{array}{l}\mathrm{N} \\
\text { Mean } \\
\mathrm{SD} \\
\mathrm{CV}(\%)\end{array}$ & $\begin{array}{l}12 \\
160.28 \\
100.061 \\
62.4\end{array}$ & $\begin{array}{l}12 \\
|7| 8.7 \mid \\
1004.005 \\
58.4\end{array}$ & $\begin{array}{l}12 \\
1731.272 \\
1005.036 \\
58.1\end{array}$ & $\begin{array}{l}12 \\
0.90 \\
1.112 \\
124.0\end{array}$ & $\begin{array}{l}12 \\
9.00 \\
9.00-16.05 \\
21.2\end{array}$ & $\begin{array}{l}12 \\
0.14 \\
0.029 \\
21.5\end{array}$ & $\begin{array}{l}12 \\
5.39 \\
1.338 \\
24.8\end{array}$ \\
\hline Treatment C & $\begin{array}{l}\mathrm{N} \\
\text { Mean } \\
\mathrm{SD} \\
\mathrm{CV}(\%)\end{array}$ & $\begin{array}{l}12 \\
97.59 \\
36.869 \\
37.8\end{array}$ & $\begin{array}{l}12 \\
1487.39 \\
590.007 \\
39.7\end{array}$ & $\begin{array}{l}12 \\
1501.10 \\
588.428 \\
39.2\end{array}$ & $\begin{array}{l}12 \\
1.07 \\
1.535 \\
143.2\end{array}$ & $\begin{array}{l}12 \\
11.50 \\
9.00-14.00 \\
18.9\end{array}$ & $\begin{array}{l}12 \\
0.14 \\
0.030 \\
21.5\end{array}$ & $\begin{array}{l}12 \\
5.23 \\
1.203 \\
23.0\end{array}$ \\
\hline
\end{tabular}

Notes: *For $t_{\max }$, median and range have been represented instead of mean and SD. Treatment A: with physical exercise; Treatment B: with heating; Treatment C: under normal conditions.

Abbreviations: SD, standard deviation; CV, coefficient of variation. 
Table 3 Geometric Least Square Mean, Ratios, 90\% Confidence Interval, ISCV and Power for Lidocaine Topical System I.8\% (in Transformed Data)

\begin{tabular}{|c|c|c|c|c|c|c|c|c|}
\hline \multirow[t]{2}{*}{ Parameter } & \multicolumn{3}{|c|}{ Geometric Mean } & \multirow{2}{*}{$\begin{array}{l}\text { Intra-Subject } \\
\text { CV (\%) }\end{array}$} & \multirow{2}{*}{$\begin{array}{l}(\mathbf{A} / \mathrm{C}) \\
\text { Ratio, \% }\end{array}$} & \multirow{2}{*}{$\begin{array}{l}\mathbf{9 0 \%} \text { Confidence } \\
\text { Intervals }(\mathrm{A} / \mathrm{C})\end{array}$} & \multirow{2}{*}{$\begin{array}{l}(\mathrm{B} / \mathrm{C}) \\
\text { Ratio, \% }\end{array}$} & \multirow{2}{*}{$\begin{array}{l}90 \% \text { Confidence } \\
\text { Intervals (B/C) }\end{array}$} \\
\hline & A & Treatment B & c & & & & & \\
\hline $\mathrm{C}_{\max }, \mathrm{ng} / \mathrm{mL}$ & 87.27 & 134.44 & 91.72 & 24.4 & 95.14 & $80.30-112.73$ & 146.57 & $|23.7|-173.66$ \\
\hline $\begin{array}{l}\mathrm{AUC}_{0-\mathrm{t}} \\
\mathrm{h} \mathrm{ng} / \mathrm{mL}\end{array}$ & 1264.16 & 1513.10 & 1400.70 & 17.9 & 90.25 & $79.65-102.26$ & 108.02 & $95.34-122.40$ \\
\hline $\begin{array}{l}\mathrm{AUC}_{0-\infty} \\
\mathrm{h} \cdot \mathrm{ng} / \mathrm{mL}\end{array}$ & 1281.92 & 1526.88 & $14 \mid 6.04$ & 17.4 & 90.53 & $80.15-102.25$ & 107.83 & $95.46-121.79$ \\
\hline
\end{tabular}

Notes: Treatment A: with physical exercise; Treatment B: with heating; Treatment C: under normal conditions.

Abbreviations: ISCV, intrasubject coefficient of variation; $\mathrm{CV}$, coefficient of variation.

Figure 1 shows that the effects of heating were mainly evident at the 9-hour time point (immediately following 20 minutes of heating starting at 8.5 hours), with little difference observed among the three treatments at other time points at which lidocaine concentrations were measured (Figure 1, Tables 2 and 3 ).

Lidocaine concentrations at 9 hours were $171.8 \pm 96.3$ $\mathrm{ng} / \mathrm{mL}$ after heating compared with $88.5 \pm 25.4 \mathrm{ng} / \mathrm{mL}$ for Treatment A and $92.9 \pm 39.7 \mathrm{ng} / \mathrm{mL}$ for Treatment C (Figure 1, Tables 2 and 3).

Thus, the effects of heating on lidocaine absorption appeared to be immediate and reversible, with no suggestion of dose dumping or discontinuation of drug delivery. Given the timing of heat application used in this study, heating increased the $C_{\max }$ via an immediate effect at the 9-hour time point, with the little overall effect on the AUC.

The median $t_{\max }$ was 9 hours for Treatment B and 11.5 hours for Treatment $\mathrm{C}$. The observed half-life was similar for Treatment B (5.390 hours) and Treatment C (5.230 hours) (Figure 1, Tables 2 and 3).

The observed intrasubject coefficient of variation for $\mathrm{C}_{\max }$ was found to be $24.4 \%$, indicating a higher variability in exposure during Treatment B (Figure 1, Tables 2 and 3).

\section{Adhesion and Irritation Analysis}

Adhesion analysis included all topical systems from 12 subjects; no systems detached during the study across all three treatment periods or were removed early for unacceptable irritation, and no subjects dropped out of the study before the end of the 12-hour application period (Table 4). The mean irritation scores for 12 subjects for all treatments were $<1$ (1=minimal erythema) after product removal.

Under normal conditions (Treatment $C$ ), all subjects had $\geq 90 \%$ adhesion throughout the administration period. Under heat conditions (Treatment B), a slight degree of lifting (score of $1, \geq 75 \%$ to $<90 \%$ ) was observed for 2 subjects at 9 and 12 hours, respectively, and at 12 hours for a third subject. Product lifting was observed for 6 subjects (50\%) under exercise conditions (Treatment A), with 2 subjects having a score of $2(\geq 50 \%$ to $<75 \%$ adhered) at some point during the 12-hour administration period. Three subjects observed to have lifting after exercise had improved adhesion at later time points within the 12-hour administration period. No subject was observed to have a score of $\geq 3$ ( $>0 \%$ to $<50 \%$ adhered) or complete detachment.

\section{Adverse Events and Safety}

A total of six AEs were spontaneously reported by four subjects during the study (Table 5); three events occurred in two subjects in Period-I. One of these subjects had a headache (twice), which was considered possibly related to the study drug and treatment (Treatment B; heat). The second subject reported lightheadedness secondary to exercise treatment (Treatment A), which was considered

Table 4 Summary Statistics of Adhesion Performance Evaluation of Lidocaine Topical System I.8\% with Physical Exercise, Heating, and Normal Conditions

\begin{tabular}{|l|l|l|l|l|l|l|l|}
\hline Statistics & Treatment* & N & Minimum & Maximum & Mean & SD & CV (\%) \\
\hline Adhesion Score & A & 12 & 0 & 2 & 0.33 & 0.389 & 116.8 \\
& B & 12 & 0 & 1 & 0.07 & 0.132 & 190.3 \\
& C & 12 & 0 & 0 & 0.00 & 0.000 & 0 \\
\hline
\end{tabular}

Notes: *Treatment A: with physical exercise; Treatment B: with heating; Treatment C: under normal conditions.

Abbreviations: SD, standard deviation; CV, coefficient of variation. 
Table 5 Summary of Adverse Events

\begin{tabular}{|c|c|c|c|c|c|}
\hline Subject Number & Period Number & Treatment Received & Adverse Event & Severity & Related to Drug \\
\hline S04 & III & B & Head cold & Mild & Not related \\
\hline S05 & $\begin{array}{l}\text { I } \\
\text { II }\end{array}$ & $\begin{array}{l}\text { B } \\
\text { C }\end{array}$ & $\begin{array}{l}\text { Headache } \\
\text { Headache }\end{array}$ & $\begin{array}{l}\text { Moderate } \\
\text { Mild } \\
\text { Moderate }\end{array}$ & $\begin{array}{l}\text { Possibly related } \\
\text { Possibly related } \\
\text { Possibly related }\end{array}$ \\
\hline $\begin{array}{l}\text { S09 } \\
\text { SI2 }\end{array}$ & I (Washout) & $\begin{array}{l}A \\
A\end{array}$ & $\begin{array}{l}\text { Menstrual cramps } \\
\text { Light headedness secondary to exercise }\end{array}$ & $\begin{array}{l}\text { Mild } \\
\text { Mild }\end{array}$ & $\begin{array}{l}\text { Not related } \\
\text { Not related }\end{array}$ \\
\hline
\end{tabular}

Notes: Treatment A: with physical exercise; Treatment B: with heating; Treatment C: under normal conditions.

unrelated to the study drug. Another AE (headache) was reported in a subject during Period-II (Treatment C), which was considered possibly related to the study drug.

AEs considered unrelated to the study drug were one subject with menstrual cramps during the PeriodI washout. Another subject reported a head cold in PeriodIII that was also not considered related to the study drug.

The most common AE was headache, which occurred in three subjects. No deaths or serious AEs were reported during the study. Vital assessments conducted throughout all treatment periods were within normal limits for all subjects.

\section{Discussion}

The results of this study show that the effects of four 30minute episodes of physical exercise on the rate and extent of lidocaine absorption from topical system $1.8 \%$ were not significant, thus, allowing for safe use of the product during moderate physical activity, as reflected in the product's prescribing information. ${ }^{7}$

Localized heating of lidocaine topical system $1.8 \%$ for 20 minutes at two different time periods resulted in a significant increase in lidocaine absorption, reflected in a higher $\mathrm{C}_{\max }$ than that observed under normal conditions, but did not significantly impact the extent of drug delivery $\left(\mathrm{AUC}_{0-\mathrm{t}}\right.$ or $\left.\mathrm{AUC}_{0-\infty}\right)$. The effects of heat on absorption appeared to be immediate and reversible, showing that the product does not undergo dose dumping or discontinuation of drug delivery. While heat exposure induces a significant increase in $\mathrm{C}_{\max }$, the level observed $(172 \mathrm{ng} / \mathrm{mL})$ was well below the systemic safety threshold of $5000 \mathrm{ng} / \mathrm{mL}$ for the avoidance of related AEs and the IV levels used to treat cardiac arrhythmias $(1000-1500 \mathrm{ng} / \mathrm{mL}){ }^{12}$ These changes appear generally consistent with data in the literature for other topical and transdermal products and are an expected thermodynamic outcome. ${ }^{10}$

Subjects were generally healthy, and vital signs were within normal ranges at rest, during heat exposure, and during physical activity. Overall, the application of lidocaine topical system $1.8 \%$ was well tolerated; six AEs reported by four subjects, with the most common $\mathrm{AE}$ being headache. Of the six reported AEs, only three were considered associated with the study drug, all of which were headache and observed in the same subject. No localized dermatologic AEs (ie, irritation, itching, blisters) were reported by any subject.

Limitations of the present study include the small size of the study population $(\mathrm{N}=12)$, ECG monitoring at baseline only and the lack of a comparator. Comparative examinations of the effects of heat and exercise between lidocaine topical system $1.8 \%$ and lidocaine patch $5 \%$ would have been of interest and should be investigated further. However, the potential deleterious effects (eg complete or partial dosedump of drug) of these conditions with lidocaine patch 5\% cannot be reasonably hypothesized or safe-guarded relative to the high drug load within the product $(700 \mathrm{mg})$. The extent and seriousness of heat exposure effects on in vivo drug absorption, pharmacodynamics, and possible adverse events of topical products are dependent on the physicochemical and pharmacological properties of the drug(s) and the drug delivery system formulation design and need to be evaluated on a case-by-case basis. ${ }^{15}$

\section{Conclusion}

The results of this study show that administration of three lidocaine topical systems $1.8 \%$, each containing $36 \mathrm{mg}$ of active compound produced sustained plasma lidocaine concentrations and was well tolerated in healthy subjects under normal conditions, with physical exercise, and with localized heating for 20 minutes with a heating pad. There was no significant effect observed on the PK profile under the exercise conditions. While heat exposure induces a significant increase in Cmax, the concentrations observed are well below ( $\sim 30$-fold) the systemic safety threshold for the avoidance of related AEs and 6- to 10- 
fold below the IV levels used to treat cardiac arrhythmias. Adequate adhesion of the system was maintained under both conditions, and the dermal irritation profile was benign.

\section{Data Sharing Statement}

The authors certify that this manuscript reports original clinical trial data. Individual participant data that underlie the results reported in this article after deidentification (text, tables, figures, and appendices) are available from Medical Affairs Department at Scilex Pharmaceuticals Inc. at Medical_Affairs@scilexpharma.com including the study protocol. Data requests should be submitted in the form of a research proposal for up to 36 months after the publication date.

\section{Ethics Approval and Informed Consent}

The sponsors and investigators state that they have obtained appropriate IRB approval from Salus Institutional Review Board in Austin, Texas or have followed the principles outlined in the Declaration of Helsinki for all human or animal experimental investigations. In addition, for investigations involving human subjects, informed consent has been obtained from the participants involved.

\section{Acknowledgments}

The authors would like to thank the investigators, their clinical staff, and the subjects who made this study possible. Nirzari Parikh, PhD, of Synergy Medical Education, provided medical writing support. This article is the sole work of the authors; stated opinions or assertions do not reflect the opinions of employers or employee affiliates listed. The article was not prepared as part of the authors' duties as federal employees where applicable.

\section{Funding}

The project supported by Shandong Key Research and development Program (Grant No. 2018GSF118110).

\section{Disclosure}

Dr Jeffrey Fudin is a speaker for Abbott Laboratories, AstraZeneca, and Acutis Diagnostics, Inc; part of the advisory board, speakers bureau, and consulting for AcelRx Pharmaceuticals, BioDelivery Sciences International, GlaxoSmithKline (GSK), Salix Pharmaceuticals, and DaiichiSankyo Incorporated; received non-financial support by collaborating publications for Scilex Pharmaceuticals; consultant for Firstox; advisory board for Human Half-Cell, Inc and Quest Diagnostics, outside the submitted work. Drs. Greuber, Vought, and Patel are full-time employees of Scilex Pharmaceuticals Inc. Dr Vought has a patent 62/762,753 pending to Scilex Pharmaceuticals Inc and was responsible for the design and conduct of the study. Dr. Nalamachu has been a consultant/speaker and has received an honorarium from BDSI, DSI, Endo, Insys, Scilex Pharmaceuticals Inc., Purdue, Pfizer Inc., Eli Lilly and Company, Collegium Pharmaceutical, Pernix Therapeutics, Daiichi-Sankyo, and AstraZeneca. Dr Erica Wegrzyn reports personal fees from Remitigate LLC and Tower Health Pain \& Addiction Symposium; is an Associate Editor in Chief for Journal of Pain Research, outside the submitted work. The authors report no other conflicts of interest in this work.

\section{References}

1. Hadley GR, Gayle JA, Ripoll J, et al. Post-herpetic neuralgia: a review. Curr Pain Headache Rep. 2016;20(3):17.

2. Mallick-Searle T, Snodgrass B, Brant JM. Postherpetic neuralgia: epidemiology, pathophysiology, and pain management pharmacology. J Multidiscip Health. 2016;9:447-454. doi:10.2147/JMDH.S106340

3. Bettinger JJ, Wegrzyn EL, Fudin J. Pain management in the elderly: focus on safe prescribing. Pract Pain Manag. 2017;17(3).

4. Shrestha M, Chen A. Modalities in managing postherpetic neuralgia. Korean J Pain. 2018;31(4):235-243. doi:10.3344/kjp.20 18.31.4.235

5. Fornasari D. Pharmacotherapy for neuropathic pain: a review. Pain Ther. 2017;6(Suppl 1):25-33. doi:10.1007/s40122-017-0091-4

6. Massengill JS, Kittredge JL. Practical considerations in the pharmacological treatment of postherpetic neuralgia for the primary care provider. J Pain Res. 2014;7:125-132. doi:10.2147/JPR.S57242

7. ZTLIDO ${ }^{\circledR}$ (Lidocaine Topical System): Prescribing Information. San Diego, California, USA: Scilex Pharmaceuticals; 2018.

8. LIDODERM ${ }^{\circledR}$ (Lidocaine Patch 5\%): Prescribing Information. Malvern, Pennsylvania, USA: Endo Pharmaceuticals; 2018.

9. Lenz TL. The effects of high physical activity on pharmacokinetic drug interactions. Expert Opin Drug Metab Toxicol. 2011;7 (3):257-266. doi:10.1517/17425255.2011.553190

10. Vanakoski J, Seppala T. Heat exposure and drugs: a review of the effects of hyperthermia on pharmacokinetics. Clin Pharmacokinet. 1998;34(4):311-322. doi:10.2165/00003088-199834040-00004

11. US Food and Drug Administration. Public health advisory: life-threatening side effects with the use of skin products containing numbing ingredients for cosmetic procedures [archive]. February 6, 2007 [updated August 19, 2013]. Available from: https://wayback. archive-it.org/7993/20171105015424/https://www.fda.gov/Drugs/ DrugSafety/PostmarketDrugSafetyInformationforPatientsandProviders/ ucm054718.htm. Accessed May 8, 2020.

12. Benowitz NJ, Meister W. Clinical pharmacokinetics of lignocaine. Clin Pharmacokinet. 1978;3:177-201. doi:10.2165/00003088-1978 03030-00001

13. Guidance for Industry. Assessing the Irritation and Sensitization Potential of Transdermal and Topical Delivery Systems for ANDAs. U.S. Department of Health and Human Services, Food and Drug Administration, ed. Rockville, MD, USA; 2018. Available from: https://www.fda.gov/media/117569/download. Accessed July 30, 2019. 
14. Food and Drug Administration. Assessing Adhesion with Transdermal and Topical Delivery Systems for ANDAs - Guidance for Industry. U.S. Department of Health and Human Services, Food and Drug Administration, ed. Rockville, MD, USA; 2018. Available from: https:/www.fda.gov/media/117569/download. Accessed July $30,2019$.
15. Hao J, Ghosh P, Li SK, Newman B, Kasting GB, Raney SG. Heat effects on drug delivery across human skin. Expert Opin Drug Deliv. 2016;13(5):755-768. doi:10.1517/17425247.2016.1136286

\section{Publish your work in this journal}

The Journal of Pain Research is an international, peer reviewed, open access, online journal that welcomes laboratory and clinical findings in the fields of pain research and the prevention and management of pain. Original research, reviews, symposium reports, hypothesis formation and commentaries are all considered for publication. The manuscrip

Submit your manuscript here: https://www.dovepress.com/journal-of-pain-research-journa management system is completely online and includes a very quick and fair peer-review system, which is all easy to use. Visit http:// www.dovepress.com/testimonials.php to read real quotes from published authors. 